of solids, liquids and gases; the traditional approach, by contrast, usually limits such explanations to the kinetic theory of gases and deals with solids and liquids in a severely empirical way. This atomistic approach has led me to discuss the structure of matter, particularly solids, at some length, but I cannot see how to understand the mechanical properties of matter in any other way. Finally, I have also interpreted the subject fairly broadly, so that at several places the text overlaps into neighbouring domains of physics, chemistry, metallurgy and engineering, in order to obtain an integrated view of the whole field as both a pure and an applied science." This is an ambitious programme and could easily become a mass of ill-digested snippets and, to use the author's own words, "a mathematical jungle". That he has escaped both dangers speaks well for his erudition, skill and ingenuity.

Starting with a discussion of the perfect gas, he then deals in succession with condensed states of matter and crystal structure. Three chapters are concerned with elasticity and the propagation of waves and vibrations in solids, and here it should be remarked that they are, to the best of our knowledge and belief, real solids and not the hypothetical homogeneous material of the classical treatment. Fluidity, viscosity and fluid mechanics are considered in Chapters 7 and 12. Surface phenomena are dealt with in Chapter 8 , while Chapters 9 and 10 are devoted to plasticity. Finally, in Chapter 11 consideration is given to the problems associated with the fracture of solids. Although the treatment throughout is concerned with the principles involved, a glance at the index will reveal the extent to which these principles are related to actual phenomena. Abrasives and autofrettage, fatigue and brittle fracture, grain growth and the Reynolds number illustrate this, a treatment which will appeal to the reader concerned with the urge to know "what is the use of it all".

Although this work will appeal to very many more, it has been written mainly "for students of physical science and engineering who are at a fairly early stage of their university courses". With this end in view the text has been kopt "simple and introductory", the only background knowledge assumed being ordinary "school science and some elementary mechanics and calculus", including some acquaintance with partial differential equations. According to the publisher's jacket, "the treatment is elementary", a claim which would not be accepted by all the students to whom it is directed. In places only the best will be really at home, but even the average student can deal with at least 90 per cent of the material and will benefit enormously thereby. The best will enjoy every word.

Few authors can bo so certain that all the work put into a volume has been so well worth while. F. C. THompson

\section{MOLECULAR ORBITALS}

Molecular Orbitals in Chemistry, Physics, and Biology Edited by Per-Olov Löwdin and Bernard Pullman. Pp. xiii +578. (New York: Academic Press, Inc.; London: Academic Press Inc. (London), Ltd., 1964.) $157 \mathrm{~s}$.

$\mathrm{A}^{\mathrm{N}}$ anonymous writer in tho University of Chicago Reports $(11, \mathrm{No} .5,1961)$ wrote of R. S. Mulliken, "his playing field has been the molecule; the ball has beon the electron. In this arena, pure eloments recombine into materials and substances which man knows with his five sensos. The agent of change is the electron, tho negative charge of electricity that locks atoms together or keeps them apart". These words, which reflect Mullikon's attitude to science, are quoted in C. A. Coulson's contribution to this volume written in tribute to Mulliken on his retirement from his chair at the University of Chicago.

Mulliken has beon involved in almost evory stage of the development of molecular quantum mechanics and molecular olectronic spectroscopy. The range of his interests is easily seen from an oxamination of the articles in this book. For example, we find papers on molecular self-consistent field theory, group theory, shapes of molecules, molecular spectroscopy, the Huckel theory of $\pi$ electron molecules, semi-empirical theories of $\pi$ electron molecules and a final set on the theory of chemical reactions and biological processes. These articles, while not reporting Mulliken's work, discuss those fields in which he has worked.

Molecular Orbitals in Chemistry, Physics, and Biology, edited by Per-Olov Löwdin and Bernard Pullman, is indeed a fitting tribute to the pioneer. Its thirty-three papers are the work of some forty-six authors. The authors themselves are drawn from the United States, Europe, Asia and Australia. Some of them have been active for as long as Mulliken. We find papers from Eyring, Pauling and Slater, three of the workers who also pioneored in this field of investigation from the beginning. There is a paper by C. A. Coulson, who since the mid-1930's has been engaged in investigations almost as wide in scopo as those of Mulliken. To list the rest of the authors would be rather pointless; let it be sufficient to say that almost all the foremost workers in molecular quantum mechanics have contributed to this volume.

The contents of the book, however, require some comment. Not very much of the work reported here is new, although it is useful to havo it collected together in one volume. The opening article by C. A. Coulson, ontitled "R. S. Mulliken-His Work and Influence on Quantum Chemistry", is very good indeed. This appreciation of Mulliken's work is itself a pocket-sized review of the work done in this field. J. C. Slater contributes the only other non-technical paper. It is a pity that this contribution is so short, because what there is makes good reading. Slater states that he has just published a volume on molecular structure and that the bibliography has three pages devoted to the work of Mulliken. The quality of the remaining papers is high, but ono is left wondering if such detail really ought to bo included in such a volume as this. I myself regret that the editors have not published any of Mulliken's work. So many of Mulliken's papers have become standard works that the editors would have rendered a definite service if one or two had been included. Although several of the authors are former students or collaborators of Mulliken there is no contribution from his laboratory. Again, this is a pity.

It may be, as the editors say, that a second volumo may be required in a few years time to cover the new contributions from Mulliken. This book, however, is a suitable way to mark the retirement of a great scientist. It is vory well produced, and the artioles are relatively free from error eithor of the factual or of the printing varioty. Unfortunately the book is very expensive. I cannot see it finding its way into many private libraries. This is unfortunate since it is the sort of book one likes to have. The publishers have done a good job both with printing and binding. Finally, tho oditors are to be congratulated on assembling such an interesting set of articles by so many front-rank theoretical chemists.

T. E. PEACOCK

\section{INTRODUCTION TO THE STUDY OF ORE DEPOSITS}

Ore Deposits

By Prof. Charles F. Park, jun., and Prof. Roy A. MacDiarmid. (A Series of Books in Goology.) Pp. $\mathrm{x}+$ 475. (San Francisco and London: W. H. Frooman and Company, 1964.) $70 s$.

T is a good many years since a text on ore deposits for students (other than translated works) was last published in the English language, although several noteworthy books on this topic have lately appeared in French, German and Russian. Recent advances in know- 